\title{
Evaluation of Dialysis Adequacy, Interdialytic Weight Gain and Quality of Life of Hemodialysis Patients within Coronavirus Disease 2019 Pandemic
}

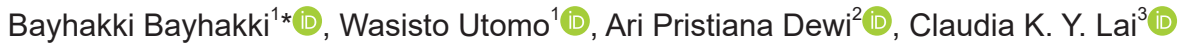 \\ ${ }^{1}$ Department of Medical Nursing, Faculty of Nursing, Riau University, Pekanbaru, Indonesia; '2Department of Community \\ Nursing, Faculty of Nursing, Riau University, Pekanbaru, Indonesia; ${ }^{3}$ Centre for Gerontological Nursing, School of Nursing, \\ The Hong Kong Polytechnic University, Hong Kong, China
}

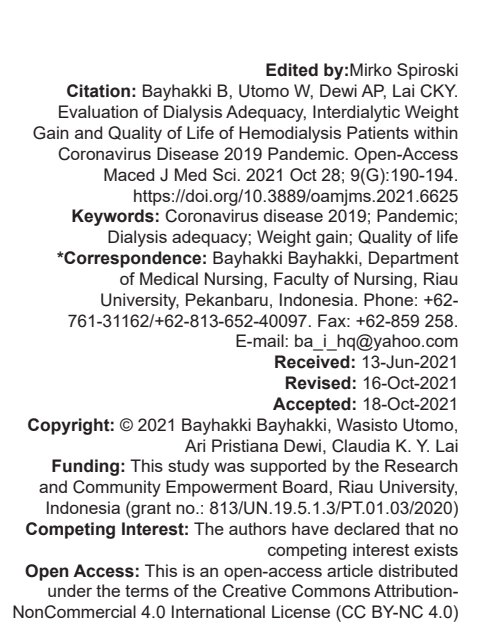

\section{Abstract}

BACKGROUND: Coronavirus disease 2019 (COVID-19) pandemic harmed the world community including hemodialysis patients. It has affected the physical and psychological status of hemodialysis patients.

AIM: This study aimed to evaluate the dialysis adequacy, interdialytic weight gain, and quality of life in patients undergoing hemodialysis during the COVID-19 pandemic.

METHODS: A quantitative study with a cross-sectional approach was conducted on 105 regular hemodialysis patients from three hemodialysis centers in Riau Province, Indonesia. The patients were purposively recruited. Data on hemodialysis adequacy and interdialytic weight gain were collected in April-May 2020 using an observation sheet, while the quality of life was measured using SF 36. To analyze the data, Pearson's correlation test and linear regression were performed.

RESULTS: Within the sample of 53 male patients was $50.5 \%$ and 52 female patients was $49.5 \%$. The mean score of dialysis adequacy during April-May was 1.75 , while the mean IDWG was $2.2 \mathrm{~kg}$, and the mean quality of life was 91.51. There was a relationship between adequacy and IDWG $(p=0.002)$, and between IDWG and quality of life $(p=0.015)$. There was no relationship between adequacy and quality of life $(p=0.360)$.

CONCLUSION: IDWG influenced the quality of life of hemodialysis patients. Health-care professionals need to help patients to keep their IDWG in the normal range to survive within COVID-19 pandemic.

\section{Introduction}

Coronavirus disease 2019 (COVID-19) is a disease caused by the coronavirus which disrupts the respiratory system which can cause death. The disease is thought to have originated in Wuhan, China which was first reported in December 2019 and has spread rapidly around the world. The World Health Organization (WHO) declared this disease an epidemic that threatens international public health on January 30 , 2020 , and later on declared this a pandemic on March 12, 2020 [1]. At present, the number of positive patients continues to increase in many countries, including Indonesia. Up to now, the number of positive cases of COVID-19 in Indonesia was 180,646 cases with a death toll of 7,616 and a total of 129,971 recoveries [2].

This disease has harmed the world community, not only in terms of health but also in various aspects of people's lives. In terms of health services, the rapid and widespread spread of the virus has caused the number of COVID-19 patients to increase rapidly so that many hospitals are unable to accommodate incoming patients and health workers are overwhelmed in providing hospital care. The increase in the number of COVID-19 patients in hospitals also makes hospitals vulnerable to being a potential source of transmission of the coronavirus. This leads to people with nonCOVID-19 diseases being unwilling to come to the hospital for treatment, therefore the number of nonCOVID-19 patients has decreased dramatically.

In Indonesia, hemodialysis patients usually come to the hemodialysis unit to undergo hemodialysis 2 or 3 times a week. Since the COVID-19 outbreak, many patients are afraid to undergo hemodialysis, which affects their health condition [3]. This can cause uncontrolled weight gain when patients no longer undergo hemodialysis as scheduled leading to deterioration in their health condition. In addition, because they do not undergo regular hemodialysis, the body's adaptability tends to change, and the amount of fluid discharged became different from their condition 
before the COVID-19 outbreak. Their health condition may also deteriorate due to psychological problems consequential to economic hardship because of reduced income due to restrictions on activities that are imposed by the government to reduce the spread of COVID-19. Moreover, the government's recommendation to stay at home causes physical activity and interactions with others to decrease. Physical and psychological problems can both affect the patient's quality of life of hemodialysis patients [4]. In hemodialysis patients, quality of life may be affected by dialysis adequacy. The adequacy may also be influenced by inter-dialytic weight gain (IDWG) [5]. Higher IDWG usually needs higher dialysis adequacy. Dialysis adequacy and IDWG may be disturbed since COVID-19 outbreak has affected the physical and psychological status of hemodialysis patients.

The previous studies on the effects of COVID-19 in hemodialysis patients have focused more on the characteristics of hemodialysis patients suffering from COVID-19 [3], [6], [7], [8], impact of drug trials on hemodialysis patients suffering from COVID-19 [9], and case report of hemodialysis patients with COVID-19 [10], [11]. No study examined hemodialysis adequacy, IDWG, and the quality of life of hemodialysis patients during the pandemic.

\section{Aim}

This study aimed to evaluate dialysis adequacy, IDWG, and quality of life of hemodialysis patients within the COVID-19 pandemic. Understanding the relationship between these variables, during the COVID19 pandemic, where almost all aspects of patient and community life are disrupted would help healthcare professionals know how to help hemodialysis patients more specifically.

\section{Methods}

This is a quantitative study with a cross-sectional approach. Patients undergoing hemodialysis in three hemodialysis centers of three Regional General Hospitals in Riau, Indonesia, were purposively recruited. The sample size was calculated using Lwanga and Lemeshow's formula [12]. A total of 105 regular hemodialysis patients participated in the study. Inclusion criteria applied in the study were undergoing hemodialysis during period of data collection, be able to communicate verbally, not suffering from COVID-19, and willing to participate in the study. Written informed consents were obtained from the patients before data collection. The study had been approved by the Ethics Committee of Faculty of Nursing, Riau University, Indonesia with approval number 44/UN19.5.1.8/KEPK.FKp/2020.
Data were collected using an SF 36 questionnaire and observation sheets. Dialysis adequacy can be calculated using $\mathrm{Kt} / \mathrm{V}$ or urea reduction ratio. In this study, hemodialysis adequacy was calculated using the $\mathrm{Kt} / \mathrm{V}$ formula since it does not need laboratory data. $K$ reflects dialyzer clearance which is expressed in blood flow rate passing through the dialyzer, $t$ is the time of a dialysis session, and V stands for volume, that is, the volume of water of a patient's body [13]. Kt/V data were obtained through a monitoring hemodialysis machine. IDWG was measured by calculating pre-dialysis weight minus post-dialysis weight of the previous dialysis sessions. The patient's weight was obtained using a scale. Kt/V and IDWG data were recorded in observation sheets. The SF-36 questionnaire was used to assess the quality of life. The patients in the study filled the questionnaire and returned it to the researchers. Correlation between dialysis adequacy, IDWG, and quality of life was analyzed using Pearson's correlation test. Simple linear regression was used to analyze the effect of dialysis adequacy and IDWG on the quality of life of hemodialysis patients.

\section{Results}

Of the 105 hemodialysis patients, there were 53 male and 52 female patients. Forty-five patients $(42.9 \%)$ were in middle age (mean age $=51.10$ and standard deviation [SD] $=11.60$ years old). Most of the patients $(89.5 \%)$ were married. About 81 or $77.1 \%$ of patients had undergone hemodialysis for longer than 6 months. The details of the patients' characteristics are shown in Table 1.

Table 1: Patient baseline characteristics $(n=105)$

\begin{tabular}{|c|c|c|}
\hline Variable & Frequency & Percentage \\
\hline \multicolumn{3}{|l|}{ Gender } \\
\hline Male & 53 & 50.5 \\
\hline Female & 52 & 49.5 \\
\hline \multicolumn{3}{|l|}{ Age } \\
\hline Late Adolescent $(17-25)$ & 2 & 1.9 \\
\hline Early adult $(26-35)$ & 9 & 8.6 \\
\hline Late adult $(36-44)$ & 18 & 17.1 \\
\hline Middle Age $(45-59)$ & 45 & 42.9 \\
\hline Elderly $(60-74)$ & 30 & 28.5 \\
\hline Late elderly $(75-90)$ & 1 & 1.0 \\
\hline \multicolumn{3}{|l|}{ Occupation } \\
\hline Entrepreneur & 16 & 15.2 \\
\hline Company Employee & 3 & 2.8 \\
\hline Carpenter & 38 & 36.2 \\
\hline Retired & 2 & 1.9 \\
\hline Jobless & 6 & 5.7 \\
\hline Farmer & 27 & 25.7 \\
\hline Teacher & 3 & 2.8 \\
\hline Hawker & 2 & 1.9 \\
\hline Government officer & 3 & 2.8 \\
\hline Student & 5 & 4.8 \\
\hline \multicolumn{3}{|l|}{ Marital Status } \\
\hline Single & 5 & 4.8 \\
\hline Married & 94 & 89.5 \\
\hline Widow/Widower & 6 & 5.7 \\
\hline \multicolumn{3}{|c|}{ Length of Undergoing HD (months) } \\
\hline$<6$ & 24 & 22.9 \\
\hline$\geq 6$ & 81 & 77.1 \\
\hline
\end{tabular}

Table 2 shows dialysis adequacy, IDWG, and quality of life had normal data distribution as evidenced 
Table 2: Scores of the variables $(n=105)$

\begin{tabular}{lllllll}
\hline Variables & Mean & Median & SD & Lowest & Highest & p-value \\
\hline Hemodialysis adequacy & 1.75 & 1.76 & 0.35 & 0.92 & 2.5 & $0.481^{\mathrm{a}}$ \\
IDWG & 2.2 & 2.17 & 0.74 & -0.12 & 4.2 & $0.779^{\mathrm{a}}$ \\
Quality of Life & 91.51 & 90 & 8.36 & 73 & 111 & $0.180^{\mathrm{a}}$ \\
\hline \multicolumn{7}{l}{ Level of significance $\mathrm{p}<0.05 ;{ }^{\text {a }}$ Kolmogorov-Simonov test. }
\end{tabular}

by normality test results where all of them had $p=$ values $(0.481,0.779$, and 0.180 , respectively $)>0.05$. The mean of dialysis adequacy in this study was 1.75 with a $\mathrm{SD}=0.35$. The lowest dialysis adequacy was 0.92 and the highest was 2.5. All hemodialysis patients received hemodialysis therapy twice a week for $4-5 \mathrm{~h}$ each time. The mean value of quality of life for hemodialysis patients in this study was 91.51 and the median $=90$ and the SD $=8.36$. The lowest quality of life score was 73 and the highest was 111 . SF-36 reflects the quality of life using the score, in which the higher the score, the higher the quality of life.

Figure 1 shows the mean of the adequacy per week during April-May 2020. The mean of adequacy decreased from 1.72 in early April continues to decline to 1.62 at the end of the month. The mean of the adequacy rose to 1.7 at the beginning of May but fell in the $2^{\text {nd }}$ week and rose again in the $3^{\text {rd }}$ week. The level declined again and in the past week of May, it was at 1.65. Although the adequacy level went up and down, overall the level was lower at the end of May when compared with the beginning of April.

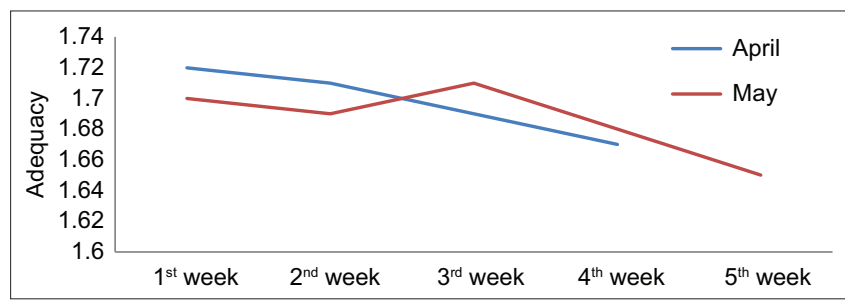

Figure 1: Hemodialysis adequacy during April-May 2020

The results of IDWG data processing (Figure 2) showed that the average IDWG in this study was $2.2 \mathrm{~kg}$ with a SD and was $2.17 \mathrm{~kg}$. The highest IDWG value was $4.2 \mathrm{~kg}$ and the lowest was $-0.12 \mathrm{~kg}$. Figure 2 shows that the mean of IDWG during April was higher than in May. In April, the highest IDWG was in week $4(2.74 \mathrm{~kg})$. In May, the highest IDWG was also in week $4(2.29 \mathrm{~kg})$. This result reflects that IDWG scores decrease from April to May.

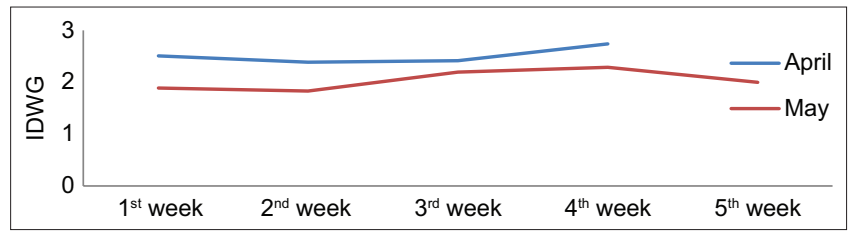

Figure 2: IDWG during April-May 2020

The results of the correlation analysis showed that there was a relationship between hemodialysis adequacy and IDWG $(\mathrm{p} 0.002<0.05)$ with $r$ value $=-0.300$ which meant higher adequacy and lower IDWG. There was no relationship between hemodialysis adequacy and quality of life ( $0.360>0.05)$. However, there was a significant relationship between IDWG and quality of life $(p 0.015<0.05)$ with $r$ value $=0.237$, meaning that higher quality of life and higher IDWG of the patients (Table 3).

Table 3: Correlational analysis of the variables $(n=105)$

\begin{tabular}{lll}
\hline Variables & Quality of life & IDWG \\
\hline Hemodialysis adequacy & $\mathrm{p}^{*}=0.360 \mathrm{a}$ & $\begin{array}{l}\mathrm{p}^{*}=0.002^{\mathrm{a}} \\
(\mathrm{r}=-0.300)\end{array}$ \\
IDWG & $\begin{array}{l}\mathrm{p}^{*}=0.015^{\mathrm{a}} \\
(\mathrm{r}=0.237)\end{array}$ \\
\hline Level of significance $\mathrm{p}<0.05$; $^{\mathrm{a} P e a r s o n ' s ~ c o r r e l a t i o n ~ t e s t . ~}$ &
\end{tabular}

Multivariate analysis used quality of life as the dependent variable and hemodialysis adequacy and IDWG as independent variables. The results of the bivariate selection showed that $p$-value for the IDWG was 0.015 while hemodialysis adequacy was 0.360 . Therefore, only the IDWG variable was included in the multivariate modeling. The $\mathrm{R}$ Square was 0.056 The $\mathrm{F}$ value was 6.138 with a p-value of 0.015 , which meant that the regression model could be used to predict the quality of life, or in other words that the IDWG could significantly predict the quality of life. The constant $B$ value was 87,125 and the IDWG was 1.939. The regression equation model could be expressed by quality of life $=87.125+1.939$ IDWG (Table 4$)$.

Table 4: Multivariate analysis of the variables $(n=105)$

\begin{tabular}{lcccc}
\hline Variables & $\mathrm{F}^{*}(\mathrm{sig})$ & $\mathrm{t}^{*}(\mathrm{sig})$ & R-square $^{*}$ & $\mathrm{~B}^{*}$ \\
\hline Constant & & & & 87,125 \\
IDWG & $6.138(0.015)$ & $2.477(0.015)$ & 0.056 & 1.939 \\
\hline
\end{tabular}

*Obtained from the linear regression test.

\section{Discussion}

Most of the respondents in this study were middle-aged and had undergone hemodialysis for more than 6 months. Several studies have also found the same patient profiles [9], [14], [15], [16] Patients who have been on hemodialysis for a long time tend to be more disciplined in observing therapy schedule despite facing obstacles because they feel the benefits of undergoing therapy [17].

The results of this study showed that the mean value of hemodialysis adequacy during the first 2 months of the COVID-19 pandemic was 1.75 with the lowest adequacy value of 0.92 , and the highest was 2.5 . KDOQI (2015) recommends adequate adequacy of 1.2 for hemodialysis therapy twice a week [18]. It means that the adequacy average in this study is above the recommendation. One study showed that increasing the adequacy value of 0.1 will reduce the mortality rate by $7 \%$ [19]. Increased adequacy also indicates effective hemodialysis for the patient [20]. Kt/ $\mathrm{V}$ below 0.80 is considered a sign of inadequate hemodialysis [21].

The high adequacy value in this study was probably due to a decrease in the $\mathrm{V}$ value which represents the volume of fluid removed during 
hemodialysis. The decrease in the volume of body fluids discharged during hemodialysis may reflect the reduced fluid intake for the few days between dialysis. Kt/V above 1.7 can also indicate signs of malnutrition [22]. Adequacy in April is higher than in May. The psychological effects of COVID-19 might have affected patients' fluid and food intake. Disturbing physical and psychological conditions can cause disturbances in various body systems including eating and drinking habits [23], [24].

The mean of IDWG during April-May from the results of this study was $2.2 \mathrm{~kg}$ with the highest IDWG value was $4.2 \mathrm{~kg}$ and the lowest was $-0.12 \mathrm{~kg}$. According to a study, the majority of patients had IDWG below $5 \%$ or about 2-3.5 kg [25]. The lowest IDWG is minus because the bodyweight pre-dialysis is lower than the bodyweight post-dialysis of the previous dialysis session. This indicates weight loss during inter-dialysis. It is rare in hemodialysis patients. It may indicate malnutrition. This result corresponds to an increase in the $\mathrm{Kt} / \mathrm{V}$ respondents of this study that are above 1.7 as a potential indicator of malnutrition [22]. Although many factors influence malnutrition, in the context of the present situation, the intra-dialysis weight gain has decreased in the respondents of this study in a situation where there are physical restrictions affecting life due to the COVID-19 pandemic.

The mean value of the quality of life of hemodialysis patients in this study was 91.51 which was measured using SF-36 where the higher the score, the higher the quality of life. The highest score of SF-36 is 100. Quality of life is an important parameter in assessing the outcome of hemodialysis therapy [26]. In general, it can be concluded that even though they live in a pandemic with various limitations, respondents in this study have a good quality of life.

In this study, there was no relationship between hemodialysis adequacy and quality of life ( $p 0.360>0.05$ ) in which other studies also found the same thing which state that adequacy cannot be used as a parameter to evaluate the quality of life [27]. The relationship between IDWG and quality of life $(p=0.015)$ and $B$ value $=1.939$ indicated that IDWG has effects on the quality of life for hemodialysis patients. IDWG that is too low can indicate malnutrition and risk of lowering the quality of life, but IDWG that is too high can also cause complications that can affect the quality of life [22].

Limitation of this study where this study did not investigate all factors influencing quality of life of the hemodialysis patients. The researchers also did not explore lifestyle of the hemodialysis patients during the pandemic. However, studying the factors influencing quality of life and lifestyle may be needed to gain more deepen understanding on the whole life of the hemodialysis patients.

\section{Conclusion}

This study showed that at the beginning of the COVID-19 pandemic the mean value of dialysis adequacy in April was higher than in May. The mean value of IDWG was higher during April compared to May. The quality of life for hemodialysis patients in this study was good. There was a relationship between hemodialysis adequacy and IDWG but no relationship between hemodialysis adequacy and quality of life. IDWG influences the quality of life of hemodialysis patients. The COVID-19 pandemic affects hemodialysis patients. Health workers working in the hemodialysis unit, especially doctors and nurses, have an important role in maintaining and increasing the quality of life of patients during the COVID-19 pandemic by helping patients to keep the patient's IDWG in the normal range so that the patients will survive within the pandemic and it will not impact on the patient's health status.

\section{References}

1. Jebril NM. World health organization declared a pandemic public health menace: A systematic review of the coronavirus disease 2019 “COVID-19." Int J Psychosoc Rehabil 2020;24:2784-95.

2. Satgas Penanganan Covid19. Peta Sebaran; 2020. p. 1. Available from: https://covid19.go.id/peta-sebaran [Last accessed on 2020 Sep 02].

3. Trivedi M, Shingada A, Shah M, Khanna U, Karnik ND, Ramachandran R. Impact of COVID-19 on maintenance haemodialysis patients: The Indian scenario. Nephrology. 2020;25(12):929-32. http://doi.org/10.1111/nep.13760

PMid:3271306032713060

4. Bayoumi MM, Saleh J, Wakeel A. Exercise programs on hemodialysis impacts patients. Qual Life Phys Fitness. 2015;23(1):192-200.

5. Theofilou P, Togas C, Vasilopoulou C, Minos C, Zyga S, Tzitzikos $\mathrm{G}$. The impact of $\mathrm{Kt} / \mathrm{V}$ urea-based dialysis adequacy on quality of life and adherence in haemodialysis patients: A crosssectional study in Greece. Health Psychol Res. 2015;3(1):1060. http://doi.org/10.4081/hpr.2015.1060

PMid:3271306026973953

6. Aydin Bahat K, Parmaksiz E, Sert S. The clinical characteristics and course of COVID-19 in hemodialysis patients. Hemodial Int. 2020;24(4):534-40. http://doi.org/10.1111/hdi.12861 PMid:3271306032730678

7. Zhang J, Cao F, Wu SK, Xiang-Heng L, Li W, Li GS, et al. Clinical characteristics of 31 hemodialysis patients with 2019 novel coronavirus: A retrospective study. Ren Fail. 2020;42(1):726-32. http://doi.org/10.1080/0886022X.2020.1796705 PMid:3271306032722980

8. Alalwan AA, Taher A, Alaradi AH. A hemodialysis patient with severe COVID-19 pneumonia. Cureus. 2020;12(5):e7995. http://doi.org/10.7759/cureus.7995

PMid:3271306032391234

9. Giaime P, Guenoun M, Pedinielli N, Narbonne H, Bergounioux JP, Solas $\mathrm{C}$, et al. Hydroxychloroquine and azithromycin tolerance 
in haemodialysis patients during COVID-19 infection. Nephrol Dial Transplant. 2020;35(8):1346-53. http://doi.org/10.1093/ndt/ gfaa191

\section{PMid:3271306032844224}

10. Ferrey AJ, Choi G, Hanna RM, Chang Y, Tantisattamo E, Ivaturi $\mathrm{K}$, et al. A case of novel coronavirus disease 19 in a chronic hemodialysis patient presenting with gastroenteritis and developing severe pulmonary disease. Am J Nephrol. 2020;51(5):337-42.

11. Sia CS, Cheong SH, Ngoh CL, Tan YH, Wong WK. Critical coronavirus disease 2019 in a hemodialysis patient: A proposed clinical management strategy. Case Rep Nephrol Dial 2020;119228:86-94.

12. Lemeshow, S, Lwanga S. Sample Size Determination in Health Studies. A Practical Manual. Geneva: World Health Organization; 1991.

13. Dehvan F, Monjazebi F, Khanghahi ME, Mohammadi $H$, Gheshlagh RG, Kurdi A. Adequacy of dialysis in Iranian patients undergoing hemodialysis: A systematic review and meta-analysis. Nephrourol Mon. 2018;10(5):e82235. http://doi. org/10.5812/numonthly. 82235 .

14. Goicoechea M, Sánchez Cámara LA, Macías N, de Morales AM, Rojas ÁG, Bascuñana A, et al. COVID-19: clinical course and outcomes of 36 hemodialysis patients in Spain. Kidney Int. 2020;98(1):27-34. http://doi.org/10.1016/j.kint.2020.04.031 PMid:3271306032437770

15. Lim JH, Park Y, Yook JM, Choi SY, Jung HY, Choi JY, et al. Randomized controlled trial of medium cut-off versus highflux dialyzers on quality of life outcomes in maintenance hemodialysis patients. Sci Rep. 2020;10(1):7780. http://doi. org/10.1038/s41598-020-64622-z

PMid:3271306032385307

16. Rehman IU, Lai PS, Kun LS, Lee LH, Chan KG, Khan TM. Chronic kidney disease-associated pruritus and quality of life in malaysian patients undergoing hemodialysis. Ther Apher Dial. 2020;24(1):17-25. http://doi.org/10.1111/1744-9987.12862 PMid:3271306031152625

17. Ali M, Wang W, Chaudhry N, Geng Y. Hospital waste management in developing countries: A mini review. Waste Manag Res. 2017;35(6):581-92. http://doi.org/10.1177/0734242X17691344 PMid:3271306028566033

18. Perez-Garcia $R$, Jaldo $M$, Alcázar $R$, de Sequera $P$, Albalate $M$, Puerta $\mathrm{M}$, et al. Unlike $\mathrm{Kt}$, high $\mathrm{Kt} / \mathrm{V}$ is associated with greater mortality: The importance of low V. Nefrologia. 2019;39(1):58-66. http://doi.org/10.1016/j.nefro.2018.04.006 PMid:3271306030075965

19. Esmaili H, Majlessi F, Montazeri A, Sadeghi R, Nedjat $S$, Zeinali J. Dialysis adequacy and necessity of implement health education models to its promotion in Iran. Int $\mathrm{J}$ Med Res Health Sci. 2016;5(10):116-21.

20. Abedi-Samakoosh M, Ahangarkani F, Aghaie N, Gholami F, Shirzad M, Naseripour Z. The relationship between the adequacy of hemodialysis and laboratory parameters. Chronic Dis J. 2017;5(1):19-27.

21. Ross EA, Paugh-Miller JL, Nappo RW. Interventions to improve hemodialysis adequacy: Protocols based on real-time monitoring of dialysate solute clearance. Clin Kidney J. 2018;11(3):394-9. http://doi.org/10.1093/ckj/sfx110 PMid:3271306029942505

22. Kahraman A, Akdam H, Alp A, Huyut MA, Akgullu C, Balaban T, et al. Impact of interdialytic weight gain (IDWG) on nutritional parameters, cardiovascular risk factors and quality of life in hemodialysis patients. BANTAO J. 2015;13(1):25-33.

23. Biniaz V, Moonaghi HK, Froutan R, Ebadi A. Subjective adequacy of dialysis; A neglected concept in hemodialysis adequacy. J Ren Inj Prev. 2018;7(3):164-70.

24. Shirazian S, Grant CD, Aina O, Mattana J, Khorassani F. Depression in chronic kidney disease and end-stage renal disease: Similarities and differences in diagnosis, epidemiology, and management. Kidney Int Reports. 2017;2(1):94-107. http:// doi.org/10.1016/j.ekir.2016.09.005

PMid:3271306029318209

25. Hara T, Kimachi M, Akizawa T, Fukuhara S, Yamamoto $Y$. Interdialytic weight gain effects on hemoglobin concentration and cardiovascular events. Kidney Int Rep. 2020;5(10):1670-8. http://doi.org/10.1016/j.ekir.2020.07.027

PMid:3271306033102959

26. Lins L, Carvalho FM. SF-36 total score as a single measure of health-related quality of life: Scoping review. SAGE Open Med. 2016;4:205031211667172. http://doi. org/10.1177/2050312116671725 PMid:3271306027757230

27. Wang R, Tang C, Chen X, Zhu C, Feng W, Li P, et al. Poor sleep and reduced quality of life were associated with symptom distress in patients receiving maintenance hemodialysis. Health Qual Life Outcomes. 2016;14(1):125. http://doi.org/10.1186/ s12955-016-0531-6

PMid:3271306027608683 